\title{
Assessment of the Relationship Between Knowledge Management Implementation and Managers' Skills (Case Study: Reezmoj System Company in Iran)
}

\author{
Mohammad Taghipour ${ }^{1}$, Kambiz Saffari ${ }^{2}$, Negin Sadri $^{3}$ \\ ${ }^{1}$ Department of Industrial Engineering, Science \& Research Branch of Islamic Azad University, Tehran, Iran \\ ${ }^{2}$ Governmental Management, Firoozkooh Branch of Islamic Azad University, Tehran, Iran \\ ${ }^{3}$ Industrial Engineering, Non-profit Institute of Higher Education, Aba - Abyek, Qazvin, Iran \\ Email address: \\ mohamad.taghipour@srbiau.ac.ir (M. Taghipour), saffarikambiz@yahoo.com (K. Saffari), neginsadri@gmail.com (N. Sadri)
}

\section{To cite this article:}

Mohammad Taghipour, Kambiz Saffari, Negin Sadri. Assessment of the Relationship Between Knowledge Management Implementation and Managers' Skills (Case Study: Reezmoj System Company in Iran). Science Journal of Business and Management.

Vol. 4, No. 4, 2016, pp. 114-120. doi: 10.11648/j.sjbm.20160404.12

Received: April 22, 2016; Accepted: May 7, 2016; Published: July 21, 2016

\begin{abstract}
The Purpose of this study is to consider the effects of knowledge management implementation on manager's skills of Reezmouj System Company. The analytical model of the research is based on the combination of the Newman and Conrad knowledge management general model and Katz (Robert Katz) managerial skills model. Research hypotheses designed were on these two models. The measurement tools of the research are questionnaires, Research hypotheses were evaluated evaluated through Pearson's statistical tests of correlation analysis, regression fitting using SPSS software. Results showed that there is a relation between knowledge management and improving managerial skills and each aspect of knowledge management are influencing on improving managers skills and their influencing rates are different in each level of manager's skills. Among the aspects of knowledge management, knowledge acquisition has the most impact on conceptual and technical skills and knowledge saving has the most impact on human skills.
\end{abstract}

Keywords: Knowledge, Knowledge Management, Managerial Skills

\section{Introduction}

By the turn of the industry-based economy towards the knowledge-based economy, organizations have forced themselves to reinforce their competitive strength depending on knowledge and information and using them in the procedure of trading. To answer the important question why some organizations are more successful, we need to understand the vital role of knowledge in them.

In general, organizations are dependent on two types of assets: tangible assets and intangible assets. What had attracted the attention of organizations until quite recently was acquiring and optimizing their tangible assets such as machinery and equipment; but today they have realized that intangible assets such as intellectual capital, experience, organizational knowledge and information are the reasons for their success and presence. Future organizations will be information-based and include experts who set their principles and approaches using the feedbacks received from colleagues, customers and managers. Relying on that the core of utilizing labor force will shift from simple and physical workers towards knowledgeable workers who will be resistant to behavioral approaches of working environments that were used in the army environments for over 100 years; thus, a revolution will appear in organizational fields.

Knowledge capital is the hidden asset of organizations that competition priorities can be reached by them if they are managed. Knowledge is essential for the survival of organizations as a resource and the condition of organizations' success is obtaining through understanding and knowledge at all levels.

Problem Statement and conceptual model of the research:

Knowledge is considered as the most strategic organizational resource, the axis of competitions and even the key point of survival. Therefore, the importance of managing 
such a strategic resource has been stated. Knowledge strategy helps organizations to determine their current and future needs using knowledge and to manage such knowledge (Akhavan and Heidari, 2007). Knowledge management is looking for achieving knowledge, wisdom and valuable experiences of workers and also implementing, restoring and preserving knowledge as assets of the organization. As Peter Drucker, "The secret of success of organizations in the $21^{\text {st }}$ century is knowledge management". Therefore, the managers of organizations, relying on better knowledge and wisdom, must gain the ability to make wiser decisions about important issues and improving functions based on knowledge. Knowledge management, in fact, is a more important issue than knowledge itself, which is looking for determine and clarify how individual and organizational knowledge are transformed into individual and group knowledge and skills (Tabarsa and Ourmazdi, 2008).

The increasing complexity of societies, science advancements and technology as consequently the increase of needs and development of organizations make a force hire efficient and skillful managers for managing organizations because the wise performance of managers will result in survival and growth of an organization (Irannejad, Pairizi; Sasangohar, 2001).

Today, companies have concluded that they must pay more attention to what they know (Intellectual capital) than what they have (Financial assets). Managers are the most important factor to ensure the success or failure of an organization and the quality of management at all levels influences the efficiency of the organization. Managerial skills of each organization and, ultimately, the quality of management of each organization determine how human resources of that organization are managed (Horsy and
Blanchard, 2006).

Knowledge management, as the tool for imposing procedures at individual, group and organizational levels in order to set conditions in which knowledge and information can be accessed by members at the right time, has been the center of attention for many researchers in scientific and organizational fields. Although research and study about knowledge management from the viewpoint of content can guide the managers and other actors to know and understand the knowledge management, it is not solely enough. In the current conditions, managers, as the major actors, look at the organizational issues from the view of function and performance and evaluate the importance and necessity of a method via considering the effects and functions of that method. Therefore, considering these matters, we decided to assess and check the effects of implanting and using knowledge management in organizations on the skills of managers using a comprehensive approach and to determine if such implanting can be effective in promoting managers' necessary skills. To do this research, a combination of the general model of knowledge management by Newman and Conrad (Abtahi and Salavati, 2006) and model of managerial skills by Katz (Horsy and Blanchard, 2006) will use. Regarding the analytical model of the research, knowledge management variables, including 1 . Knowledge acquisition 2. Knowledge reservation 3. Knowledge distribution and 4 . Knowledge utilization, are considered as the independent variables while managers' managerial skills, including 1 . Perceptual skills 2. Human skills 3. Technical skills are seen as the dependent variables. There seems to be a relationship between knowledge management and managers' managerial skills.

To do this research the following model was used:



Fig. 1. Conceptual model of the research (assessment of effects of implanting knowledge management system on managers' skills). 


\section{Hypotheses of Study}

\subsection{The Main Hypothese}

There is a relationship between the knowledge management system and managers' skills promotion in Reezmoj System Company.

\subsection{The Secondary Hypotheses}

1. There is a relationship between the knowledge management system and the promotion of perceptual skills of the managers in Reezmoj System Company.

2. There is a relationship between the knowledge management system and the promotion of human skills of the managers in Reezmoj System Company.

3. There is a relationship between the knowledge management system and the promotion of technical skills of the managers in Reezmoj System Company.

\section{Methodology}

The method of this study for collecting data was descriptive survey study and for the relationship between variables was the correlation. In this study, the target is to determine the extent of coordination of changes of the two variables to declare how much managers' skills will improve if knowledge management in implanted. The statistical society of the study is all of the personnel of Reezmoj System Company, which are 240 members according to the statistical information in 2015. To select the sample group, simple accidental sampling, and Cochran formula were used and 148 members were assessed. To collect data two questionnaires of knowledge management (Fong and Choi, 2009) and managers' skills (researcher conducted) were used. The first one included 25 parts and the second one included 37 , both consisting 5-level Likert answer range. Cronbach alpha was used to estimate the stability of the questionnaires with 0.88 and 0.83 , respectively moreover, the logical method was used, to determine the validity of the questionnaires. Rephrase-SPSS software was used to analyze the data so; the data was analyzed both descriptively and deductively. Chlomogrov Smirnov test was used to detect normality or abnormality of the data and regarding the normal being of the data, correlation factor of Pearson and Regression analysis were used.

\subsection{Findings}

Considering the statistical analysis which was provided in descriptive and deductive statistics, the current condition of Reezmoj System Company and the deductive statistics findings are as follows:

1. Regarding gender, $\% 77.9$ of the samples were male and $\% 22$. Therefore the major part of the samples were male.

2. Regarding the educational level of the samples, $\% 12.4$ had Diploma or below, \%28.3 Associated degree, \%49 Bachelor's and \%10.3 Master's or higher. Then, more than $\% 80$ had university degrees.

3. Regarding the work experience, $\% 29$ had less than 5 years of experience, $\% 40$ between 6 and 10 years, $\% 25.5$ between 11 and 15 years and $\% 5.5$ more than 15 years. Thus the samples were quite young.

4. Regarding the job category, $\% 3.4$ were junior or senior managers, \%19.3 department heads, \%33.8 supervisors and $\% 43.4$ other clerks and workers.

5. Description of the condition of knowledge management in Reezmoj System Company: To describe such a thing, the results showed that the average knowledge management in every aspect exceeded the medium (equaling 3). Regarding the answers of the samples, knowledge management ranks 3.62 out of 5 which is higher than medium.

6. Description of the condition of managers' skills in Reezmoj System Company: To describe such a thing, the results showed that the average knowledge management in every aspect exceeded the medium (equaling 3). Regarding the answers of the samples, managers' skills ranks 3.5 out of 5 which is higher than medium.

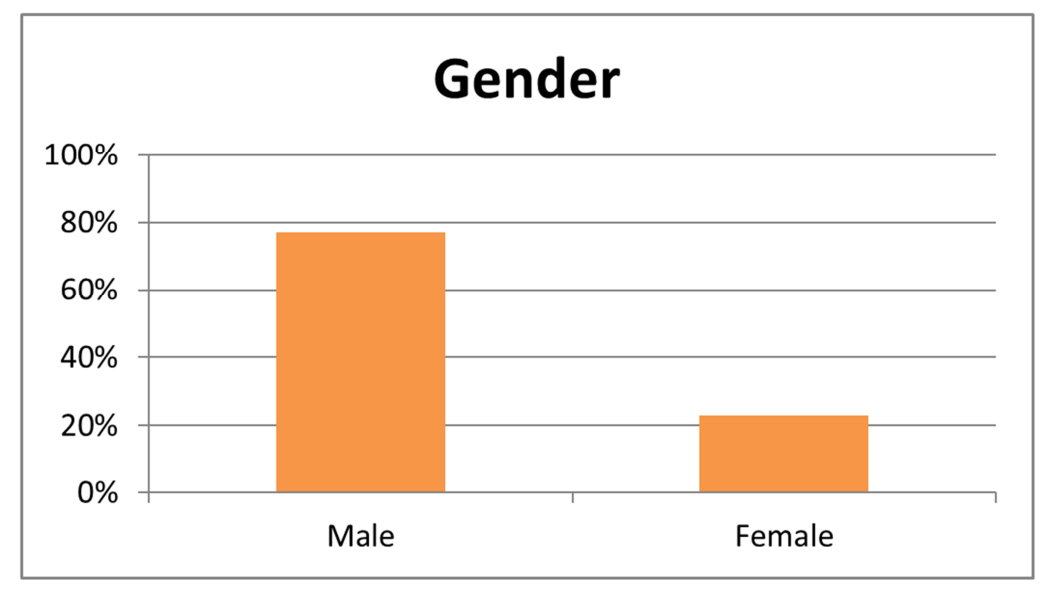

Fig. 2. Gender of the samples. 


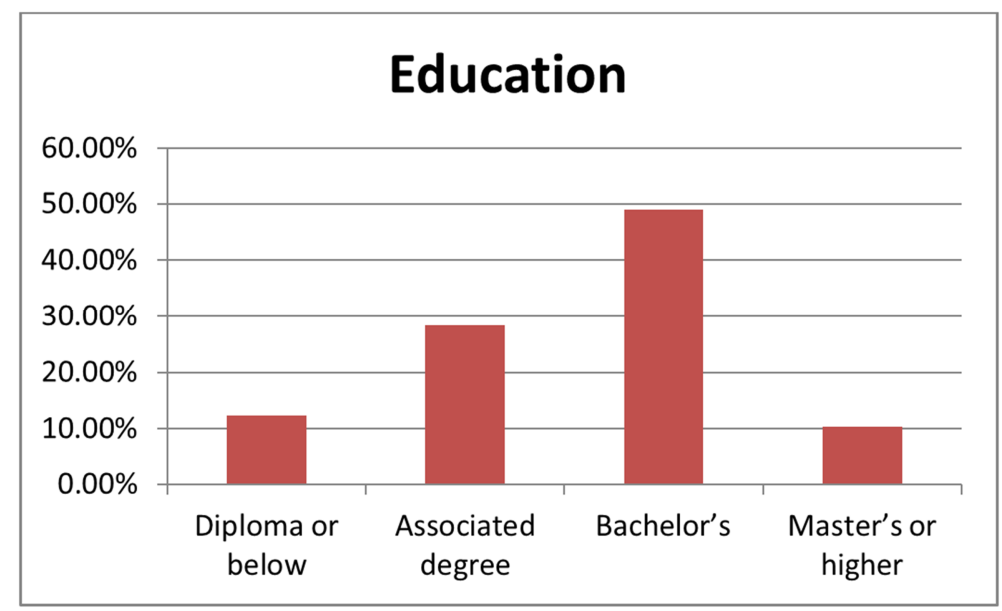

Fig. 3. Educational level of the samples.



Fig. 4. Work experience of the samples.

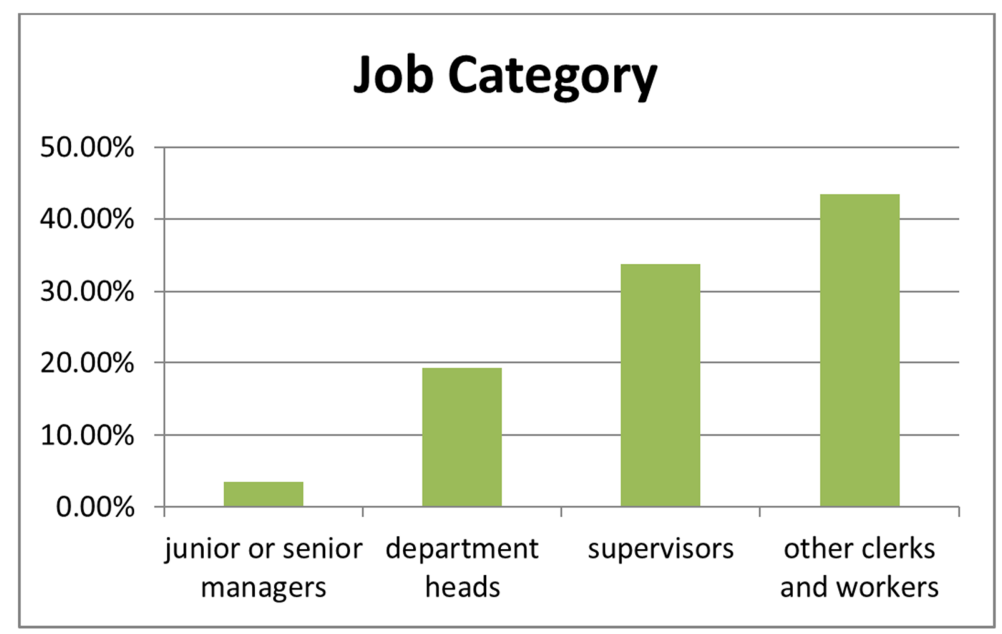

Fig. 5. Job Positions of the samples.

\begin{tabular}{|c|c|c|c|c|c|c|c|c|}
\hline Index & $\mathrm{N}$ & Missing & Min & Max & Range & Mean & Median & Mod \\
\hline Knowledge Management & 145 & 0 & 1.73 & 4.58 & 2.84 & 3.62 & 3.81 & 3.73 \\
\hline
\end{tabular}

Fig. 6. The condition of knowledge management in Reezmoj System Company from the view of the samples. 


\begin{tabular}{|c|c|c|c|c|c|c|c|c|}
\hline Index & $\mathrm{N}$ & Missing & Min & Max & Range & Mean & Median & Mod \\
\hline Managers Skill & 145 & 0 & 2.1 & 4.84 & 2.74 & 3.5 & 3.62 & 3.53 \\
\hline
\end{tabular}

Fig. 7. The condition of managers' skills in Reezmoj System Company from the view of the samples.

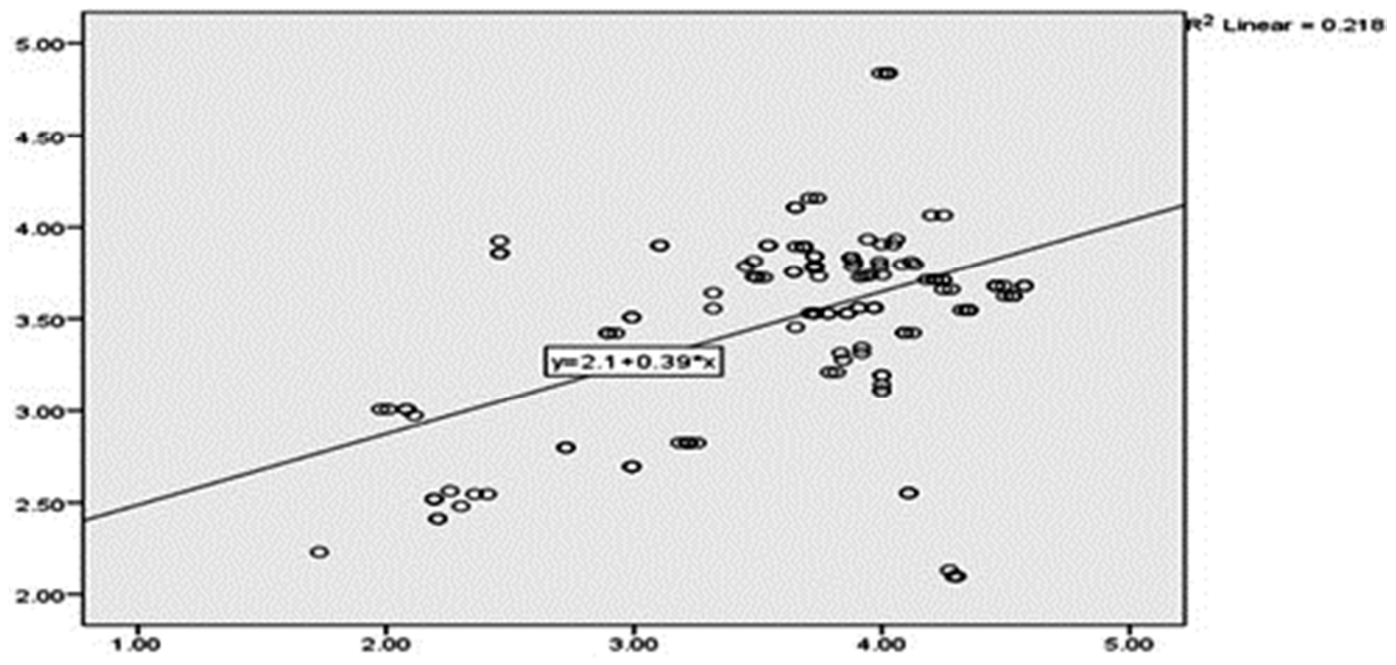

Fig. 8. Linear equation of fitting for managers' skills regarding knowledge management.

\subsection{Findings of the Test of Theses of the Study Using Regression and Correlation Analysis}

\subsubsection{Analysis of Correlation for the Primary Thesis}

There is a relationship between the knowledge management and managers' skills promotion in Reezmoj system Company. To assess the correlation between knowledge management and managers' skills promotion the Pearson correlation factor was used and the results showed that there was a meaningful relationship between them at $\% 99$ with the correlation of 0.47 , resulting in acceptance of the primary thesis of the study about the existence of a relationship between knowledge management and managers' skills promotion.

\begin{tabular}{|c|c|c|c|c|}
\hline Durbin-Watson & $\begin{array}{c}\text { Std.Error of the } \\
\text { Estimate }\end{array}$ & $\begin{array}{c}\text { Adjusted R } \\
\text { Square }\end{array}$ & R Square & R \\
\hline 2.016 & 0.49133 & 0.213 & 0.218 & 0.467 \\
\hline
\end{tabular}

Fig. 9. Quality indexes model between knowledge management and managers' skills.

To assess the extent of this effect as fitting, regression model was analyzed and the following was resulted:

\begin{tabular}{|c|c|c|c|c|c|}
\hline \multicolumn{2}{|c|}{ ANOVA } & & \\
\hline Model & Sum of Squares & df & Mean Square & & Sig \\
\hline Regression & 9.633 & 1 & 9.633 & 39.91 & 0 \\
\hline Residual & 34.521 & 143 & 0.241 & & \\
\hline Total & 44.154 & 144 & & & \\
\hline
\end{tabular}

Fig. 10. Variance analysis of the knowledge management and managers' skills model.

\begin{tabular}{|c|c|c|c|c|c|}
\hline \multirow{2}{*}{ Model } & \multicolumn{2}{|c|}{ Unstandardized Coefficients } & \multirow{2}{*}{$\begin{array}{c}\text { Standard } \\
\text { Coefficients }\end{array}$} & \multirow{2}{*}{$\mathrm{t}$} & \multirow{2}{*}{ Sig } \\
\cline { 2 - 4 } & $B$ & Std.Error & Beta & & \\
\hline (Constant) & 2.101 & 0.226 & & 9.3 & 0 \\
\hline Knowledge Management & 0.387 & 0.061 & 0.467 & 6.317 & 0 \\
\hline
\end{tabular}

Dependent Variable:Managers Skill

Fig. 11. Regression factors of the knowledge management and managers' skills.

$$
\mathrm{Y}=2.01+(0.387) \mathrm{X}+\dot{\varepsilon}
$$

In other words, if knowledge management is added a single value, managers' skills will increase for 0.38 .

\subsubsection{Analysis of Correlation for the Secondary Theses Analysis of Correlation for the First Secondary Thesis}

First secondary thesis: There is a relationship between knowledge management and perceptual skills of the managers

To assess this, Pearson test was used and the results showed that there was a meaningful relationship between them at $\% 99$ with the correlation of 0.42 , and the relationship between knowledge management and promotion of the perceptual skills of the managers was proven.

To assess the effectiveness of each aspect of knowledge management in managers' perceptual skills promotion, multiple regression model (Enter method) was used.

\begin{tabular}{|c|c|c|c|c|}
\hline Durbin-Watson & $\begin{array}{c}\text { Std.Error of the } \\
\text { Estimate }\end{array}$ & $\begin{array}{c}\text { Adjusted R } \\
\text { Square }\end{array}$ & R Square & $\mathrm{R}$ \\
\hline 1.614 & 0.58209 & 0.155 & 0.179 & 0.423 \\
\hline
\end{tabular}

Fig. 12. The indexes of efficiency model between knowledge management and perceptual skills of the managers. 


\begin{tabular}{|c|c|c|c|c|c|}
\hline \multicolumn{7}{|c|}{ ANOVA } \\
\hline Model & $\begin{array}{c}\text { Sum of } \\
\text { Squares }\end{array}$ & df & Mean Square & F & Sig \\
\hline Regression & 10.32 & 4 & 2.58 & 7.614 & 0 \\
\hline Residual & 47.36 & 140 & 0.339 & & \\
\hline Total & 57.756 & 144 & & & \\
\hline
\end{tabular}

Fig. 13. Variance analysis of the knowledge management and managers perceptual skills promotion model.

\begin{tabular}{|l|c|c|c|c|c|}
\hline \multirow{2}{*}{ Model } & \multicolumn{2}{|c|}{$\begin{array}{c}\text { Unstandardized } \\
\text { Coefficients }\end{array}$} & $\begin{array}{c}\text { Standard } \\
\text { Coefficients }\end{array}$ & \multirow{2}{*}{$\mathrm{t}$} & \multirow{2}{*}{ Sig } \\
\cline { 2 - 4 } & $B$ & Std.Error & Beta & & 0 \\
\hline (Constant) & 1.929 & 0.272 & & 7.087 & 0.047 \\
\hline Knowledge Acquistion & 0.224 & 0.13 & 0.245 & 1.722 & 0.445 \\
\hline Knowledge Reservation & 0.102 & 0.132 & 0.114 & 0.766 & 0.264 \\
\hline Knowledge Distribution & -0.108 & 0.097 & -0.132 & -1.121 & 0.115 \\
\hline Knowledge Implemention & 0.15 & 0.095 & 0.196 & 1.587 & 0.19 \\
\hline
\end{tabular}

Fig. 14. Regression factors of the knowledge management and perceptual skills.

On the basis of "B", regression equation can be as follows:

$$
\mathrm{Y}=1.93+(0.224) \mathrm{X} 1+(0.102) \mathrm{X} 2-(0.108) \mathrm{X} 3+(0.15) \mathrm{X} 4
$$

Regarding " $\mathrm{B}$ ", knowledge acquisition factor $\left(\mathrm{X}_{1}\right)$ is bigger than the other values. Also, its Beta value is higher which shows that this factor has a bigger share in managers' perceptual skills promotion than the other ones.

\subsubsection{Analysis of Correlation for the Second Secondary Thesis}

Second secondary thesis: There is a relationship between knowledge management and human skills of the managers

To assess this, Pearson test was used and the results showed that there was a meaningful relationship between them at $\% 99$ with the correlation of 0.48 , and the relationship between knowledge management and promotion of the human skills of the managers was proven.

\begin{tabular}{|c|c|c|c|c|}
\hline Durbin-Watson & $\begin{array}{c}\text { Std.Error of } \\
\text { the Estimate }\end{array}$ & $\begin{array}{c}\text { Adjusted R } \\
\text { Square }\end{array}$ & R Square & $\mathrm{R}$ \\
\hline 2.16 & 0.614 & 0.21 & 0.232 & 0.482 \\
\hline
\end{tabular}

Fig. 15. The indexes of efficiency model between knowledge management and human skills of the managers.

To assess the effectiveness of each aspect of knowledge management in managers' perceptual skills promotion, multiple regression models (Enter method) was used. "F" in fig. 17 , considering $\operatorname{sig}=0$ at 0.95 means that regression is meaningful and at least one aspect of knowledge management has effects on the managers' human skills promotion.

\begin{tabular}{|c|c|c|c|c|c|}
\hline \multicolumn{7}{|c|}{ ANOVA } \\
\hline Model & $\begin{array}{c}\text { Sum of } \\
\text { Squares }\end{array}$ & df & Mean Square & F & Sig \\
\hline Regression & 15.951 & 4 & 3.988 & 10.577 & 0 \\
\hline Residual & 52.782 & 140 & 0.377 & & \\
\hline Total & 68.733 & 144 & & & \\
\hline
\end{tabular}

Fig. 16. Variance analysis of the knowledge management and managers human skills promotion model.

\begin{tabular}{|c|c|c|c|c|c|}
\hline \multirow{2}{*}{ Model } & \multicolumn{2}{|c|}{$\begin{array}{c}\text { Unstandardized } \\
\text { Coefficients }\end{array}$} & $\begin{array}{c}\text { Standard } \\
\text { Coefficients }\end{array}$ & \multirow{2}{*}{$\mathrm{t}$} & \multirow{2}{*}{ Sig } \\
\cline { 2 - 3 } & $B$ & Std.Error & Beta & & \\
\hline (Constant) & 1.85 & 0.287 & & 6.442 & 0 \\
\hline Knowledge Acquisition & 0.05 & 0.137 & 0.05 & 0.362 & 0.718 \\
\hline Knowledge Reservation & 0.536 & 0.14 & 0.553 & 3.837 & 0 \\
\hline Knowledge Distribution & -0.091 & 0.102 & -0.102 & -0.895 & 0.372 \\
\hline Knowledge Implemention & -0.051 & 0.1 & -0.061 & -0.51 & 0.611 \\
\hline
\end{tabular}

Dependent Variable: Human Skills

Fig. 17. Regression factors of the knowledge management and human skills.

On the basis of "B", regression equation can be as follows:

$$
\mathrm{Y}=1.85+(0.05) \mathrm{X} 1+(0.536) \mathrm{X} 2-(0.091) \mathrm{X} 3-(0.051) \mathrm{X} 4
$$

Regarding " $\mathrm{B}$ ", knowledge reservation factor $\left(\mathrm{X}_{2}\right)$ is bigger than the other values. Also, its Beta value is higher which shows that this factor has a bigger share in managers' human skills promotion than the other ones.

\subsubsection{Analysis of Correlation for the Third Secondary Thesis}

First secondary thesis: There is a relationship between knowledge management and technical skills of the managers

To assess this, Pearson test was used and the results showed that there was a meaningful relationship between them at $\% 99$ with the correlation of 0.44 , and the relationship between knowledge management and promotion of the technical skills of the managers was proven.

\begin{tabular}{|c|c|c|c|c|}
\hline Durbin-Watson & $\begin{array}{c}\text { Std.Error of } \\
\text { the Estimate }\end{array}$ & $\begin{array}{c}\text { Adjusted R } \\
\text { Square }\end{array}$ & R Square & $\mathrm{R}$ \\
\hline 1.875 & 0.525 & 0.168 & 0.191 & 0.438 \\
\hline
\end{tabular}

Fig. 18. The indexes of efficiency model between knowledge management and technical skills of the managers.

To assess the effectiveness of each aspect of knowledge management in managers' perceptual skills promotion, multiple regression models (Enter method) was used. " $F$ " in fig. 20, considering sig $=0$ at 0.95 means that regression is meaningful and at least one aspect of knowledge management has effects on the managers' technical skills promotion. 


\begin{tabular}{|c|c|c|c|c|c|}
\hline \multicolumn{7}{|c|}{ ANOVA } \\
\hline Model & $\begin{array}{c}\text { Sum of } \\
\text { Squares }\end{array}$ & df & $\begin{array}{c}\text { Mean } \\
\text { Square }\end{array}$ & F & Sig \\
\hline Regression & 9.138 & 4 & 2.284 & 8.288 & 0 \\
\hline Residual & 38.591 & 140 & 0.276 & & \\
\hline Total & 47.729 & 144 & & & \\
\hline
\end{tabular}

Fig. 19. Variance analysis of the knowledge management and managers technical skills promotion model.

\begin{tabular}{|c|c|c|c|c|c|}
\hline \multirow{2}{*}{ Model } & \multicolumn{2}{|c|}{$\begin{array}{c}\text { Unstandardized } \\
\text { Coefficients }\end{array}$} & $\begin{array}{c}\text { Standard } \\
\text { Coefficients }\end{array}$ & \multirow{2}{*}{$\mathrm{t}$} & \multirow{2}{*}{ Sig } \\
\cline { 2 - 3 } & $B$ & Std.Error & Beta & & \\
\hline (Constant) & 2.307 & 0.246 & & 9.396 & 0 \\
\hline Knowledge Acquisition & 0.158 & 0.117 & 0.19 & 1.348 & 0.18 \\
\hline Knowledge Reservation & 0.131 & 0.119 & 0.162 & 1.094 & 0.276 \\
\hline Knowledge Distribution & 0.039 & 0.087 & 0.052 & 0.447 & 0.655 \\
\hline Knowledge Implemention & 0.053 & 0.085 & 0.076 & 0.617 & 0.538 \\
\hline
\end{tabular}

Dependent Variable: Technical Skills

Fig. 20. Regression factors of the knowledge management and human skills.

On the basis of "B", regression equation can be as follows:

$$
\mathrm{Y}=2.37+(0.158) \mathrm{X} 1+(0.131) \mathrm{X} 2+(0.039) \mathrm{X} 3+(0.053) \mathrm{X} 4
$$

Regarding " $\mathrm{B}$ ", knowledge acquisition factor $\left(\mathrm{X}_{1}\right)$ is bigger than the other values. Also, its Beta value is higher which shows that this factor has a bigger share in managers' technical skills promotion than the other ones.

\section{Conclusion and Discussion}

The results showed that implanting knowledge management is useful in the managers' skills promotion at Reezmoj System Company and among the aspects of knowledge management, knowledge acquisition has the greatest effect on perceptual skills (Planning, DecisionMaking, Controlling and supervising, Creativity and innovation) and also, technical skills (Expert actions and computer usage); also reservation of knowledge has the greatest share in managers' human skills promotion (Communication, Motivation, Leadership, and guidance).

\section{References}

[1] Abtahi, Seyed Hassan and Salavati, Adel., (1385), Knowledge Management in Organization, Peyvand-e-No Publishing, First Printing.

[2] Akhavan, Peyman and Oliaee, Alnoush and Help of Mamaghani, Nasrin and Saghafi, Fateme., (1389), the Development of Processes Cycle of Knowledge Management Based on effective factors of Knowledge Management success, Journal of Science and Technology Policy, Third year, Number 2, Winter 1389, Pages 1-11.

[3] Akhavan, Peyman and Haidari, Safanaz, (1387), Customer Knowledge Management Method for Competitive Advantage, Journal of tomorrow Management, Fifth year, Number 18, Pages 24-40.

[4] L. Doft, Richard, (1388), Organization Design and Theory, Translated by Ali Parsian and Syed Mahmaee Erabi, the Cultural Research office, Sixth Printing, Volume 1 and 2.

[5] Amin Beidokhti, Ali Akbar and Makvand Hosseini, Shahrokh and Ehsani, Zahra. (1389), Investigation of the Relationship Between Organizational Culture and Knowledge management in Semnan City Education System, Journal of Rahbord, the Twentieth Year, Number 59, Summer 1390, pagess 191- 216.

[6] Tabarsa, Gholam Ali and vavermazdi, Noushin. (1387), Measuring and Explaining the Underlying Factors on the Establishing of case study knowledge management: National Iranian Oil Products Distribution Company (N. I. O. P. C), of Tehran, Journal of Management Message, Number 26, Pages 39- 69.

[7] Momeni, Mansour. and Faal Ghayoomi, Ali, (1391), Statistical Analysis by SPSS, Tehran publication: Mansour. Momeni, seventh printing.

[8] Fong, Patrick S. W. and Choi, Sonia K. Y., (2009), The processes of knowledge management in professional services firms in the construction industry: a critical assessment of both theory and practice, journal of knowledge management, Vol. 13, No. 2, pp 110-126

[9] Starbuck, William H. (1992), learning by knowledge- intensive firms, journal of management studies, Vol. 6, No. 5, pp 24-35

[10] Yu, S. - H., Kim, Y. -G \& Kim, M. - Y (2007), 15. Do we know what really drives KM, performance. Journal of knowledge management, pp. 39-53. 